\title{
As Metodologias Ativas e a Aprendizagem Significativa como determinantes na produção de Tecnologias Educacionais
}

\author{
Signe D.C.M. Silva1, Ianca Sobrinho1, Késsia L. Dutra1, Tristan Lima1, William B. \\ Silva1 \\ 1 Departamento de Mídias Digitais - Universidade Federal da Paraíba (UFPB) \\ Campus Universitário I - João Pessoa - PB - Brazil \\ signedaysedyahoo.com.br; iancaasobriinho@gmail.com; \\ dutraissek@gmail.com; tristan.lima2@gmail.com; \\ williamresista@gmail.com
}

\begin{abstract}
This is a report of triangular teaching, research and extension practice that has as its objective the integral formation of students of the " $X$ " Course of the Federal University of " $X$ " and which has been under development for five years with significant results. The action aims to understand the dynamics between the use of Active Methodologies and their interactions with the production of Digital Media for Education based on Meaningful Learning. Three students were followed and working techniques focused on Active Methodologies were applied. The data collected and processed through Content Analysis (Laurence Bardim) and Triangulation Analysis (Augusto Trivinos) gives us assurance of objectives and goals achieved.
\end{abstract}

Resumo. Trata-se de um relato de prática triangular de ensino, pesquisa e extensão que tem por objeto a formação integral de estudantes do Curso de " $X$ " da Universidade Federal de " $X$ " e que já está em desenvolvimento há cinco anos com resultados expressivos. A ação tem por objetivo compreender as dinâmicas entre o uso de Metodologias Ativas e suas interações com a produção de Mídias Digitais para a Educação com base na Aprendizagem Significativa. Três estudantes foram acompanhados e a eles foram aplicadas técnicas de trabalho com foco Metodologias Ativas. Os dados coletados e tratados por meio da Análise de Conteúdo (Laurence Bardim) e da Análise por Triangulação (Augusto Trivinõs) nos dá segurança de objetivos e metas alcançadas.

\section{Motivações e propósitos}

Há anos que estudiosos de todo o mundo tentam encontrar respostas para o hiato existente entre os altos investimentos em tecnologias para a facilitação da aprendizagem e os resultados pífios alcançados pela grande maioria dos investidores, quer sejam instituições de ensino, governos ou acionistas de grupos educacionais. No Brasil são décadas de discussões e milhões em recursos investidos em qualificação de docentes, melhoria da infraestrutura e compra de tecnologias, no entanto, as estatísticas e as provas de aferição internacional não confirmam que avançamos. No que diz respeito à condição do professor temos pouco a dizer neste texto, nosso foco, aqui, é a aprendizagem do estudante por meio de práticas que estimulam sua vontade de estudar. Em alguns casos a mobilização de recursos educacionais e de estímulo à aprendizagem, 
sem custo algum, faz mais efeito do que qualquer outro recurso financeiro investido.

O Projeto DIAS - Design Instrucional para uma Aprendizagem Significativa, de ensino, pesquisa e extensão é uma ação educativa triangular voltada ao desenvolvimento e a produção de tecnologias para uso em processos educacionais em vigência desde 2015 no âmbito do Curso de Comunicação em Mídias Digitais da UFPB - Universidade Federal da Paraíba. Seu posicionamento e ações estratégicas têm por objetivo o letramento digital e a produção de objetos de aprendizagem para o uso de professores e estudantes dos diversos nichos educacionais, assim como o despertar de vocações nas áreas de Educação, Comunicação e Design Educacional por meio das bases teóricometodológicas da Teoria da Aprendizagem Significativa proposta pelo Psiquiatra Americano David Ausubel.

Para além de extensão universitária, no eixo do ensino, se faz presente nas disciplinas de Introdução ao Design Instrucional (Código 1414132) e Tecnologias e Educação à Distância (Código GDMDI0115) e no eixo de pesquisa está vinculado ao Grupo de Pesquisa UFPB/CNPq. Comunicação, Tecnologias e Multimídias para a Educação (Cinco Publicações em 2018) tendo como objeto de estudos as dinâmicas entre as tecnologias em Mídias Digitais e as Metodologias Ativas acreditadas como elemento fundamental para uma Aprendizagem Significativa, coletados e tratados os dados por meio da Análise de Conteúdo (Laurence Bardim) e da Análise por Triangulação (Augusto Trivinõs). Atualmente o projeto possui vínculo com três pesquisadores em duas Universidades Portuguesas e escoa sua produção em dois eventos: o Mídias Pitch (Segunda Edição em 2019) e a Bit.Week (Sétima Edição em 2019).

No decorrer dos cinco anos de prática pedagógica por meio da pesquisa e a extensão e suas relações, alguns elementos foram se agregando à proposta de trabalho aqui apresentada. Por um lado contamos com a experiência de professores líderes de extensão e pesquisa em educação e em práticas de trabalho inovativas que constituem-se na pedra fundamental e de sustentação das discussões de conceitos e teorias caras aos envolvidos. Por outro lado, estudantes que nos procuram com o objetivo de redirecionar suas atividades acadêmicas, em sua maioria sem foco ou propósitos definidos, fato desencadeador de desinteresse e desejo de abandono do curso de graduação e suas possibilidades. Para o presente texto pinçamos três experiências exitosas vivenciadas por estudantes que foram "recuperados" a partir de conceitos simples e que com o decorrer do tempo chegaram a posição de bolsistas e pesquisadores.

\section{Alguns fundamentos para a discussão}

Como todo movimento no âmbito da educação o primeiro passo dado foi o acolhimento dos interessados e a compreensão do objeto para que os seus fundamentos teóricos fossem postos em construção permanente pelos estudiosos das áreas envolvidas. Agrupamos as seguintes categorias de análise: Design Instrucional, Aprendizagem Significativa, Formação por Competências e Metodologias Ativas:

Entendemos por Design Instrucional o proposto por Filatro (2004, p. 64): “ $A$ ação intencional e sistemática de ensino que envolve o planejamento, o desenvolvimento e a utilização de métodos, técnicas, atividades, materiais, eventos e produtos educacionais em situações didáticas específicas, a fim de facilitar a aprendizagem humana a partir dos princípios de aprendizagem e instrução conhecidos".

Por Aprendizagem Significativa, acolhemos o que diz Ausubel (1978, p. 41 apud Moreira, 2006, p. 19): "A essência do processo de aprendizagem significativa é que ideias simbolicamente expressas sejam relacionadas, de maneira substantiva (não literal) e não arbitrária, ao que o aprendiz já sabe, ou seja, a algum aspecto de sua estrutura cognitiva especificamente relevante (isto é, um subsunçor) que pode ser, por exemplo, 
uma imagem, um símbolo, um conceito ou uma proposição já significativas.

Na perspectiva da Formação por Competências, de acordo com Perrenoud (1999, p. 69) é um processo de aprendizagem onde "as competências são construídas somente no confronto com verdadeiros obstáculos, em um processo de projeto ou resolução de problemas", ou seja, a partir de significados reais.

Entendemos que o que Móran diz sobre Metodologias Ativas se aproxima de nosso objetivo de estudo e concepção de categoria analítica: Metodologias Ativas são estratégias de ensino centradas na participação efetiva dos estudantes na construção do processo de aprendizagem, de forma flexível, interligada e híbrida. Ou seja, o estudante atua, desenvolve, pesquisa e propõe em seu processo de aprendizagem.

A partir destas concepções partimos para o entendimento de que existem três tipos de aprendizagem (Cognitiva, Afetiva e Psicomotora) e seguimos com conceitos de Pedagogia, Heutagogia e Andragogia e das abordagens de ensino (Comportamentalista, Cognitivista e Humanista) segundo Moreira (1999) e Kenski (2014). Posteriormente, o problema abordado ancora-se no pensamento de Gomez, dado o fato de que o CCMD tem como objetivo formar produtores de conteúdo para mídias digitais, o que em sua quase totalidade absorve e introduz na universidade estudantes com intimidade com o mundo virtual. De acordo com a autora: "Estamos caminhando para uma fase de convergência e integração das mídias. Tudo começa a integrar-se com tudo, a falar com tudo e com todos. Tudo pode ser divulgado em alguma mídia. Todos podem ser produtores e consumidores de informação. A digitalização traz a multiplicação de possibilidades de escolha, de interação. A mobilidade e a virtualização nos libertam dos espaços e tempos rígidos, previsíveis, determinados. O mundo físico se reproduz em plataformas digitais e todos os serviços começam a poder ser realizados física ou virtualmente. Há um diálogo crescente, muito novo e rico entre o mundo físico e o chamado mundo digital, com suas múltiplas atividades de pesquisa, lazer, de relacionamento e outros serviços e possibilidades de integração entre ambos, que impactam profundamente a educação escolar e as formas de ensinar e aprender a que estamos habituados. As mudanças que estão acontecendo na sociedade, mediadas pelas tecnologias em rede, são de tal magnitude que implicam - a médio prazo - em reinventar a educação como um todo, em todos os níveis e de todas as formas. [grifo nosso]. (Gomez, 2010, p. 9).

É inegável que o "uso da internet está abrindo um caleidoscópio de modos de apropriação nos mais diversos âmbitos" (GOMEZ, 2010, p. 11), no entanto, a defesa de um conhecimento significativo, contextual, tácito e vivencial, é um caminho ao equilíbrio nas relações entre professor e aluno, numa era em que o aluno, por incontáveis possibilidades e circunstâncias 'acessa' a informação numa velocidade impossível ao professor de alcançar e manter em níveis confortáveis. Sobrariam quais caminhos para a realização de uma formação que favorecesse o "aprender a conhecer, aprender a fazer, aprender a viver juntos e aprender a ser"? (WERTHEIN, 2000, p. 22).

Preliminarmente uma perspectiva metodológica foi pinçada em Cavalcanti (1999) que recomenda que conceitos "andragógicos", ou seja, fundadores do aprendizado de adultos sejam introduzidos ao ensino superior, favorecendo aos alunos o desenvolvimento de métodos pessoais de estudo, levando-os a uma aprendizagem mais significativa: a) tirando proveito da experiência acumulada pelos alunos; b) propondo problemas, novos conhecimentos e situações sincronizadas com a vida real; c) justificando a necessidade e utilidade de cada conhecimento; d) envolvendo alunos no planejamento e na responsabilidade pelo aprendizado; e) estimulando e utilizando a motivação interna para o aprendizado; e, f) facilitando o acesso, os meios, o tempo e as oportunidades.

Em Ausubel (apud Moreira, 1999, p. 153) encontramos que a aprendizagem 
significativa é um processo por meio do qual uma nova informação relaciona-se com um aspecto especificamente relevante da estrutura do conhecimento do indivíduo, ou seja, este processo envolve a interação da nova informação com uma estrutura de conhecimento específica existente. Assim, a aprendizagem significativa pode ser alcançada a partir de uma proposta educacional de caráter andragógico, considerando-se as particularidades do aprendizado de adultos-universitários.

Finalmente, Perrenoud (1999, p. 69) trouxe-nos que "as competências são construídas somente no confronto com verdadeiros obstáculos, em um processo de projeto ou resolução de problemas", ou seja, a partir de significados reais. Assim, outra possibilidade de dar sentido e significado à aprendizagem é o estabelecimento de conhecimentos, habilidades e atitudes 'úteis' ou de real significação à solução de problemas concretos. Neste caminho, Küller e Rodrigo (2013, p. 75) sugerem 07 (sete) passos metodológicos para uma aprendizagem voltada ao desenvolvimento de competências: a) contextualização e mobilização; b) definição da atividade de aprendizagem; c) organização da atividade de aprendizagem; d) coordenação e acompanhamento; e) análise a avaliação das atividades de aprendizagem; f) acesso a outras referências; e, g) síntese e aplicação.

Bases teóricas acolhidas, procedimentos metodológicos foram construídos em Santos (2008, p. 73) que defende que não há mais espaço para a repetição automática, descontextualizada e sem significação. Ele enfatiza que a aprendizagem significativa pressupõe sete atitudes que podem favorecer a postura de quem queira adotar o modelo proposto por Ausubel, e assim fizemos: a) Dê sentido ao conteúdo, pois toda aprendizagem parte de um significado contextual e emocional (usando organizadores prévios - infográficos); b) Especifique, depois da contextualização, levando o aluno a perceber as características específicas do que está sendo estudado (análise do currículo do curso); c) Favoreça a compreensão, que levará à construção do conceito que poderá ser utilizado em diversos contextos (escolha do eixo de atuação); d) Leve à definição, de forma clara e através das palavras do próprio aluno, dos conceitos que foram construídos (construção em grupos); e) Provoque a argumentação, após a definição, através do relacionamento lógico dos diversos conceitos (via linhas de argumentação); f) Viabilize a discussão, incentivando o raciocínio através dos argumentos e dos conceitos construídos (aplicação de enquetes através dos Questionários Google); g) Leve o conhecimento para a vida, do aluno, através da possibilidade de intervenção em sua realidade e da transformação da mesma (associação aos disparos de notícias publicadas no Facebook). Sem esse propósito, qualquer aprendizagem seria inócua.

Conceitos básicos e introdutórios postos, o Problema encontrado foi: em que medida o desenvolvimento de Objetos de Aprendizagem é potencializado com a aplicação de Metodologias Ativas garantindo-se efetivamente uma Aprendizagem Significativa?

Por Hipótese inicial acreditamos que as dinâmicas e interações adequadas, propostas pelas chamadas Metodologias Ativas, possibilitam uma maior e melhor produtividade na construção de Objetos de Aprendizagem favorecendo uma real $e$ efetiva Aprendizagem Significativa.

O Objetivo Geral é "Compreender as dinâmicas entre o uso de Metodologias Ativas e suas interações com a produção de Mídias Digitais para a Educação com base na Aprendizagem Significativa"

Já os Objetivos Específicos: Conhecer e compreender as características específicas, usos, aplicações e resultados pretendidos das chamadas Metodologias Ativas; Testar e analisar as dinâmicas entre o uso de Metodologias Ativas e a produção de Objetos de Aprendizagem no âmbito do Curso de Comunicação em Mídias Digitais da UFPB e do Projeto DIAS de Pesquisa e Extensão; Propor a aplicação de Metodologias Ativas à produção de Objetos de Aprendizagem segundo as aproximações 
mais compatíveis entre teoria e prática.

\section{Os Marcos Metodológicos Iniciais: como fazemos?}

Em primeiro lugar é importante dizer que todas as ações que a equipe do Projeto DIAS desenvolve são fruto do desejo de seus articuladores. Nenhum movimento é feito sem que propósitos claros estejam associados. Estamos organizados como um projeto multifuncional onde o ensino, a pesquisa e a extensão se entrelaçam mas as escolhas e propósitos dos articuladores são determinantes e determinados em suas ações.

Considerando-se a multidisciplinaridade no desenvolvimento de Mídias Digitais (pré-produção, produção e pós-produção) a relação ensino-pesquisa-extensão é sempre bem-vinda e favorável a uma formação integral do estudante. Em nossa realidade as práticas de Ensino estão contempladas na aquisição de conhecimentos teóricos por meio das disciplinas do currículo do Curso de Bacharelado em Comunicação em Mídias Digitais: de Metodologia do Trabalho Científico em Mídias Digitais, de Imagens Digitais I, II e III, de Infografia I e II, de Internet I e II, de Edição de Vídeo I e II, Editoração I e II, de Áudio I e II, que compõem o alicerce 'básico' para a realização deste projeto além das disciplinas Tecnologias e Educação à Distância e a Optativa de Tecnologias e Educação à Distância. A produção desenvolvida nas referidas disciplinas é escoada por meio do evento anual intitulado Mídias Pitch, onde os projetos de objetos para a aprendizagem são validados publicamente.

As atividades de pesquisa estão diretamente relacionadas aos objetos de estudo de cada docente e cada discente que se agregam ao Projeto DIAS. São estabelecidos marcos referenciais que permeiam todas as pesquisas e são definidas as estratégias de desenvolvimento dos temas e objetos. Atualmente as categorias são as já anunciadas: Design Instrucional ou Design Educacional, Aprendizagem Significativa, Metodologias Ativas e Pedagogias do Afeto. Em 2019 agregamos as Inteligências Múltiplas aos nossos estudos.

A ação de Extensão já está consolidada por meio de um projeto premiado e em funcionamento há 5 (cinco) anos. Sua principal linha de ação é o multiletramento digital de docentes das Redes Públicas no Estado da Paraíba. No decorrer dos cinco anos foram realizadas oficinas, palestras e workshops com uma média de 300 (trezentas) pessoas atendidas por ano. Em 2018 foram atendidas 500 (quinhentas) pessoas numa profícua parceria com o Governo do Estado da Paraíba por meio das Escolas Integrais de Educação Cidadã.

A proposta de Metodologia contempla o levantamento do 'Estado da Arte' das Metodologias Ativas e das demais categorias que sedimentam este projeto, a construção do conhecimento de forma coletiva, participativa e de abordagem construtivista, a partir dos fundamentos da Aprendizagem Significativa, que no pensamento de Ausubel (1978 apud Moreira 2006) preconiza que "o fator mais importante que influencia a aprendizagem, é aquilo que o aprendiz já sabe. Averigue isso e ensine-o de acordo”. As técnicas de Análise de Conteúdo (Bardin) e Triangulação (Trivinõs) serão aplicadas para a melhor compreensão dos dados levantados.

Segundo Bardin (1977, p. 33-4) "a Análise de Conteúdo é um conjunto de técnicas análise das comunicações e, ainda, pode ser uma análise dos significados (a análise temática), embora possa ser também uma análise dos significantes (análise léxica, análise dos procedimentos)". Por Técnica de Triangulação de Dados Trivinõs (1987, p. 138-9) entende-se por uma análise de objeto a partir de três perspectivas: processos e produtos centrados no sujeito, elementos produzidos pelo meio do sujeito e, finalmente, processos e produtos originados pela estrutura sócio-econômica e cultural no qual está inserido o sujeito. 
Deste modo as ações foram cumpridas e as metas realizadas a partir da definição do estudante de seu planejamento pessoal, incluindo-se as tarefas planejadas/a serem realizadas por ele, a concepção de seus Mapas Mental e Conceitual e a definição de suas estratégias de produção.

A Avaliação foi mediadora e formativa, a cada conclusão de módulo/ação, ou seja, após a construção e vivência do processo metodológico, culminando com a concepção de um Objeto de Aprendizagem e a análise de suas interações com Metodologias Ativas. A mesma se deu junto e com o estudante, a partir de seu planejamento pessoal em dois momentos: individualmente e coletivamente.

Todas as dinâmicas são tratadas por meio de um grupo de trabalho no WhatsApp e um Grupo no Facebook:

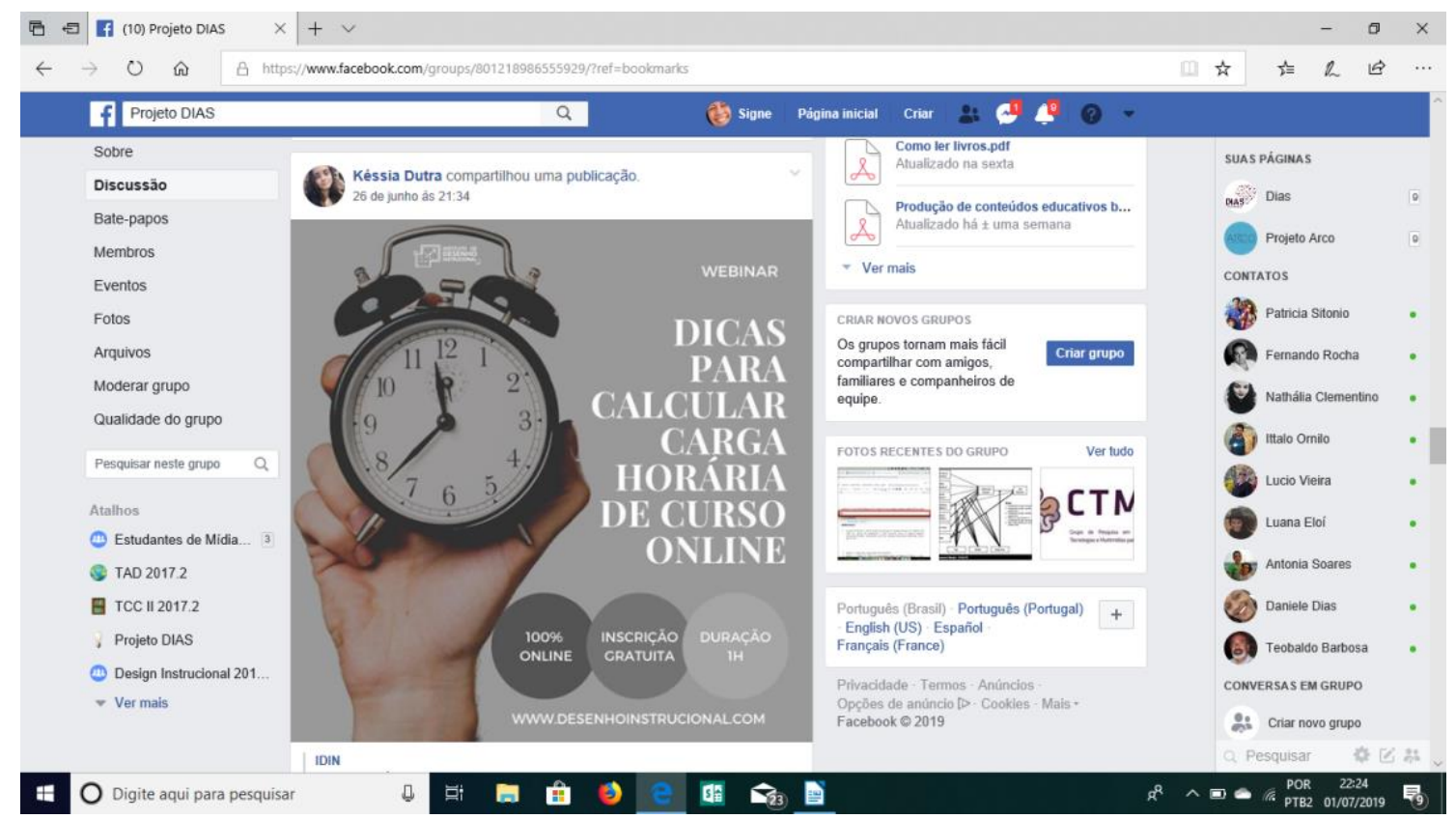

Figura 1: Grupo de Trabalho no Facebook, 2015-2019.

\section{Os Três Casos Objeto Aqui}

Foram três os primeiros casos de sucesso e que aproximam-se da finalização com objetos de aprendizagem consolidados. Para os três foram aplicados o mesmo modus operandi de organização de tarefas, a partir das respostas às seguintes perguntas:

1. O que você mais gostou/gosta de fazer em sua trajetória acadêmica? O que te instiga e motiva?

2. Em quais autores ou teorias você fundamentou seus interesses? Quais as categorias analíticas você definiu para seu trabalho e como organizou sua agenda de trabalho?

3. O que te estimularia a desenvolver com extremo interesse e prazer? Qual o seu objetivo e propósito ao desenvolver esse projeto?

Respondidas as perguntas e compreendidas as dinâmicas intelectuais do estudante passamos a conhecer melhor seu perfil, quais sejam:

Primeiro: Caso A, estudante do sexo feminino que vamos chamar de Maria e 
tem 23 anos. Apenas estuda e é sua primeira graduação. Casada, sem filhos, $30 \%$ do curso em andamento. Procurou a equipe para desabafar sobre a falta de objetivos, foco e propósitos não estabelecidos com a escolha do Curso de Graduação. Possui competências pessoais como o domínio da leitura e da escrita, autonomia e bom trânsito com tecnologias em mídias digitais. Reconhece-se como detentora de competências do que chama de "autoeducação", que consiste em saber: o que estudar, como estudar, como organizar e sistematizar os estudos, como ler em variados níveis e diferentes tipos de livros, como fazer anotações do percurso de aprendizagem para se autoavaliar na perspectiva do que já sabe e do que ainda precisa aprender. Interesse especial por áudio e confecção de Podcast. Sonha em ter sua própria plataforma de EaD.

Segundo: Caso B, estudante do sexo masculino que chamaremos de Pedro, 30 anos, segunda graduação. É formado em Letras Inglês-Português e é concursado como Professor do Governo do Estado da Paraíba. Solteiro, sem filhos, $40 \%$ do curso em andamento. Chegou no projeto aos prantos por ter sido vítima de assédio moral por parte de um docente. Extrema dificuldade com códigos de programação o que o coloca em posição de vulnerabilidade com alguns docentes. É um apaixonado por cinema e domina todas as ferramentas para a produção de argumento, roteiro, captação, edição e distribuição de vídeos, com os quais aprimorou seus conhecimentos e conteúdos no curso de Mídias Digitais, todavia não sabia como ampliar esses conhecimentos e colocá-los em prática em seu projeto de Cinema Educativo sui generis na escola onde trabalha.

Terceiro: Caso C, estudante do sexo feminino, chamaremos de Lia. Tem 25 anos e trabalha com o pai em um negócio da família. Está na primeira graduação mas passou por uma escola técnica federal e possui boas noções na área. Chegou ao grupo desmotivada e com reprovações sucessivas em uma disciplina de baixa complexidade por conta de faltas excessivas. Possui grande apreço pela arte e é protagonista de movimentos de empoderamento da mulher negra. Tem redação própria e é exímia fotógrafa. Desenvolveu um método próprio de fotografia e tem interesse em dar cursos e publicar um livro.

Os três casos chegaram no grupo com problemas de aceitação, autoestima e com estresse pós desentendimento com docentes do curso. Os três demonstraram interesse em trancar ou abandonar o curso. Os três possuíam ideias interessantes e algumas intervenções em andamento. Com o acolhimento passamos ao processo de compreensão de suas histórias e reestabelecemos os propósitos dos mesmos.

Posteriormente ao primeiro contato e com a equipe as estratégias de trabalho e pesquisa foram estabelecidas e as leituras e itinerários formativos definidos em conjunto com os mesmos, tendo como norte as categorias de análise que sustentam as ações do Projeto DIAS: Design Instrucional a partir da obra de Andréa Filatro, Aprendizagem Significativa a partir da obra de David Ausubel, Formação por Competências a partir da obra de Philippe Perrenoud e Metodologias Ativas a partir da obra de José Moran.

Para além dos autores pré-estabelecidos elencamos os autores que já sedimentavam os interesses dos três estudantes e suas categorias de trabalho: Henry Wallon e sua pedagogia do afeto, Baruch Espinosa e o desejo, a alegria e a tristeza, finalizando com os princípios da autoeducação de Olavo de Carvalho.

\section{Resultados Preliminares}

Até o momento deste evento os resultados apresentados pelos três estudantes são os seguintes:

Primeiro: Caso A, após dois anos de estudos desenvolveu um curso online para ser feito a distância sobre Introdução à Autoeducação, a partir de práticas pedagógicas 
clássicas de educação que formaram intelectuais durante séculos no Ocidente. Disponibilizou o curso no Ambiente Virtual de Aprendizagem Moodle Cloud e está com 35 (trinta e cinco) inscritos com a formação em andamento. Cursou algumas disciplinas em Educação e Design Instrucional e vivenciou a extensão universitária, que contribuiu para o desenvolvimento da sua personalidade e o seu amadurecimento intelectual, principalmente no que diz respeito a sua forma de interação com públicos. No momento encontra-se na fase final de construção do Trabalho de Conclusão de Curso. Já publicou três trabalhos em congressos nacionais e internacionais sobre a história das tecnologias educacionais e descrevendo o processo de produção do curso online sobre autoeducação.

Segundo: Caso B, após um ano de estudos redimensionou sua atuação no Projeto de Cinema Educativo com a produção concomitante de uma cartilha com abordagem na construção de narrativas ficcionais. Seu objetivo é auxiliar a outros professores do ensino básico com estratégias de ensino via Plataforma Moodle e um Ambiente Virtual no Facebook, além de um canal no Youtube. Buscou associar as disciplinas e conteúdos estudados no curso com obras clássicas voltadas e também a usar o que aprendeu nas disciplinas de argumento, roteiro, ensino à distância, e no projeto Dias, o discente usou as metodologias aplicadas nessas disciplinas e no projeto Dias para fortalecer seu projeto de cinema na escola, trazendo aprendizagem significativa para seu trabalho e ambiente acadêmico, assim, devido a estas metodologias o aluno conseguiu se manter no curso e agora o mesmo encontra-se na fase e finalização do Trabalho de Conclusão de Curso, o qual usa da aprendizagem significativa um dos pilares para se manter no curso e usar isso para outras atividades profissionais.

Terceiro: Caso C, a mais nova do grupo tem seis meses de atuação. É uma brilhante fotógrafa e possui sensibilidade notável com o que chama de "Fotografia Afetiva". Desenvolveu uma técnica própria que possui narrativas e atos no processo de construção da imagem fotográfica. No momento está pesquisando seus referenciais teóricos em fotografia, design, afetividade e imaginário. Também está economizando recursos para um estágio residência com um dos grandes nomes a fotografia nos Estados Unidos da América.

\section{Palavras Norteadoras de Possíveis Conclusões}

Todo o trabalho desenvolvido está relacionado apenas a fazer com que os estudantes reestabeleçam novos valores e propósitos em sua vida e trajetória acadêmica. $\mathrm{O}$ estabelecimento de itinerários formativos é um elemento facilitador dos caminhos a serem traçados e vivenciados e o encontro da literatura que fundamenta as suas ações. $\mathrm{O}$ Design Instrucional é a estratégia encontrada para a estimulação de uma Aprendizagem Significativa. As discussões sobre a afetividade são realizadas com o objetivo de ressignificar relações desgastadas e promover uma convivência mais suportável com os agressores.

No momento todos os envolvidos estão trabalhando na melhoria dos Ambientes de Trabalho no Moodle e na replicação em comunidades de suas experiências. Temos muito o que aprender mas acima de tudo muito a compartilhar sobre uma pedagogia voltada ao fortalecimento das interações humanas sem que se perca o foco da produtividade, o desenvolvimento e a criação de novos produtos educacionais.

Acreditamos na formação integral do estudante, mesmo o do ensino superior. Suas aflições, medos e inseguranças são motivos para intervenção e faz parte do trabalho do educador. A experiência de acompanhamento dos três estudantes aqui apresentados nos dá certezas em relação à necessidade de se estabelecer confiança, respeito e afeto no decorrer do amadurecimento de sua capacidade intelectual, 
habilidades e atitudes.

Cremos numa Aprendizagem Significativa como mote a uma vida cheia de propósitos.

\section{Referências}

Laurence, B. (1977). Análise de Conteúdo. Lisboa: Edições 70.

William B. N. (2014). Aprendizagem baseada em projetos. Educação diferenciada para o século XXI. Porto Alegre: Penso.

Jonathan. B. (2018). Aprendizagem invertida: para resolver o problema do dever dE casa. Porto Alegre: Penso.

Tony. B. (2009). Mapas Mentais: métodos criativos para estimular o raciocínio e usar ao máximo o potencial de seu cérebro. Rio de Janeiro: Sextante.

Fausto, C.; Thuinie, D. (2018). A sala de aula inovadora: estratégias pedagógicas para fomentar o aprendizado ativo. Porto Alegre: Penso.

Roberto de A. C. (1999). Andragogia: a aprendizagem nos adultos. In: Revista de Clínica Cirúrgica da Paraíba. N 6, Ano 4, (Julho).

Pedro. D. (2015). Aprender como autor. São Paulo: Atlas.

Andrea, F. (2004). Design instrucional contextualizado: educação e tecnologia. São Paulo: Editora SENAC São Paulo. . (2008). Design instrucional na prática. São Paulo: Pearson-Prentice Hall, 2008. Saraiva. ; Sabrina, C. (2015). Produção de conteúdos educacionais. São Paulo: SP, . (2018). Como preparar conteúdos para EaD. São Paulo: Saraiva Educação.

; Carolina, C. C. (2018). Metodologias INOV-ativas na educação presencial, à distância e corporativa. São Paulo: Saraiva Educação.

FIRJAN. Horizon Report (2012). Panorama Tecnológico para o Ensino Fundamental e Médio Brasileiro. New Media Consortium (NMC) e Sistema FIRJAN.

Ricardo, F. (2019). Método Trezentos: aprendizagem ativa e colaborativa para além do conteúdo. Porto Alegre: Penso.

Margarita V. G. (2010). Cibercultura, formação e atuação docente em rede: guia para professores. Brasília: Líberlivro.

Luiz, F. M. G.; Ana C. C. P. (2015). A Psicologia e o processo educativo: teoria e prática docente. São Paulo: Edições Loyola.

Vani, K. (2014). Teorias e abordagens pedagógicas. São Paulo: Centro Universitário SENAC São Paulo - Educação Superior a Distância.

José, A. K.; Natália, F. R. (2013). Metodologia de desenvolvimento de competências. Rio de Janeiro: SENAC Nacional.

Maria C. S. M.; Suely, F. D. R. G. (2007). Pesquisa Social: teoria, método e criatividade. $25^{\text {a }}$ ed. revista e atualizada. Petrópolis: RJ, Vozes.

Angélica, M.; J. António, M.; Ana C. A. (2012). Educação On-Line: pedagogia e aprendizagem em plataformas digitais. Santo Tirso: De Facto Editores, Portugal. [Coleção Formare Guias Práticos].

Marco, A. M. (1999). Teorias de aprendizagem. São Paulo: EPU. 
. (2006). A teoria da aprendizagem significativa e sua implementação em sala de aula. Brasília: Editora da Universidade de Brasília, 2006. 2010 .

. (2010). Mapas conceituais e aprendizagem significativa. São Paulo: Centauro,

Philippe, P. (1999). Construir as competências desde a escola. Porto Alegre: Artes Médicas Sul.

Andréia, F. R.; Priscila K. P. S. (2006). A contribuição do Design Instrucional das Dimensões da Educação para o desenvolvimento de Objetos de Aprendizagem. In: ANAIS do XXVI Congresso da SBC, 14 a 20/07/2006, Campo Grande, MS.

Júlio C. F. S. (2011). Aprendizagem Significativa: modalidade de aprendizagem e o papel do professor. $4^{\mathrm{a}}$ ed. Porto Alegre: Editora Mediação.

Sammya, F. T. (2014). Desenvolvimento de projetos educacionais: mídias e tecnologias. São Paulo: Érica/Saraiva.

Augusto N. S. T. (1987). Introdução à pesquisa em Ciências Sociais: a pesquisa qualitativa em educação. São Paulo: Atlas.

Jorge A. V.; Marco A. M. (2009). A Teoria da Aprendizagem Significativa. Sua fundamentação e implementação. Coimbra, Portugal: Edições Almeidina S/A.

Jorge, W. (2000). Fundamentos da nova educação. Brasília: UNESCO.

Fausto, Z. (2016). Contra a escola: ensaio sobre literatura, ensino e educação liberal. Campinas: SP, Vide Editorial. 